Saudi Journal of Oral and Dental Research

Abbreviated Key Title: Saudi J Oral Dent Res

ISSN 2518-1300 (Print) |ISSN 2518-1297 (Online)

Scholars Middle East Publishers, Dubai, United Arab Emirates

Journal homepage: http://scholarsmepub.com/sjodr/

Original Research Article

\title{
Correlation of Impacted Mandibular Third Molar \& Inferior Alveolar Nerve Canal- A Clinico Radiographic Study
}

Dr. Rohit Singh ${ }^{1}$, Dr. Revati Singh ${ }^{2}$, Dr. Supriya Singh ${ }^{3 *}$, Dr. Amit Kumar ${ }^{4}$, Dr. Shahi Kunar ${ }^{5}$, Dr. Jazib Nazeer ${ }^{6}$

${ }^{1}$ MDS, Lecturer, Department of Prosthodontics, Crown Bridge and Implantology, Patna Dental College And Hospital, Patna, Bihar, India

${ }^{2}$ MDS, Sen Resident, Department of Oral Surgery, Patna Medical College and Hospital, Patna, Bihar, India

${ }^{3}$ MDS, Lecturer, Department of Oral Medicine and Radiology, Consultant, Patna, Bihar, India

${ }^{4}$ MDS, Secturer, Oral and Maillofacial Surgery Patna Dental College and Hospital, Patna, Bihar, India

${ }^{5}$ MDS, Consultant, Department of Orthodontics, Patna, Bihar, India

${ }^{6}$ MDS, Lecturer, Department of Oral Pathology, Patna Dental College and Hospital, Patna, Bihar, India

DOI: $10.36348 /$ SJODR.2019.v04i12.007 $\quad$ | Received: 07.11.2019| Accepted: 21.11 .2019 | Published: 03.12 .2019

*Corresponding author: Dr. Supriya Singh

\section{Abstract}

Introduction: Mandibular third molar is commonly encountered impacted teeth. The present study aimed to assess relation of mandibular canal wit IANC. Materials \& Methods: The present study was conducted on 82 patients with impacted mandibular third molar of both genders requiring surgical extraction. Patients underwent OPG and CBCT. Images thus obtained were analyzed by oral and maxillofacial radiologist followed by classification of Michele. Results: Out of 82 patients, males were 48 and females were 34. Darkening of roots (DR) was seen in 14 males and 10 females, diversion of canal (DC) in 10 males and 6 females, narrowing of canal (NC) in 8 males and 5 females, presence of cortication in 10 males and 7 females and interruption of white line (IWL) in 6 males and 6 females. The difference was significant $(\mathrm{P}<0.05)$. Maximum number of subtype 3A relation was seen followed by subtype 1B, subtype 3A, subtype 3B, subtype 1A, subtype 4B etc. Conclusion: Authors found that impacted mandibular third molar surgery may lead to damage to inferior alveolar canal. Therefore a radiographic imaging with OPG and CBCT may be useful in preventing damage to the nerve.

Keywords: Cone beam computed tomography, third molar, Inferior alveolar canal.

Copyright @ 2019: This is an open-access article distributed under the terms of the Creative Commons Attribution license which permits unrestricted use, distribution, and reproduction in any medium for non-commercial use (NonCommercial, or CC-BY-NC) provided the original author and source are credited.

\section{INTRODUCTION}

Mandibular third molar is commonly encountered impacted teeth. There is requirement of surgical extraction which demand careful evaluation of anatomical landmarks. The reason for extraction can be orthodontic or prophylactic. Mandibular canal is the landmark which is associated with the mandibular second and third molar. The proximity of impacted third molar with inferior alveolar canal (IAC) needs more attention as there is chances of injury to the nerve during extraction of teeth [1].

The iatrogenic injury can result in nerve damage leading to paresthesia of the chin and lower lip. IAN paresthesia is transient or permanent prolonged sensory deficit and/or abnormal sensation in the lower jaw, mental region and lower lip of the affected side. There is higher prevalence of IAN paresthesia following third molar extraction which ranges between $0.4 \%$ and $8 \%$. Permanent paresthesia may lead to functional deficits, and a decreased quality of life [2].
Panoramic images are widely used in the assessment of proximity if IANC with mandibular third molar. Radiographic signs such as darkening, narrowing or deflection of the root, dark and bifid apex of the root, interruption of cortical outline of mandibular canal, canal diversion or narrowing, islandshaped apex were indicative of proximity between third molar and IAC on panoramic radiographs [3].

The limitation of panoramic images is lack of third dimension. Cone-beam computed tomography (CBCT) can define the several types of relationships in a buccal/lingual, mesio- distal and superior- inferior direction. Michele et al., [4] proposed new radiological classification of relationship of IANC with mandibular molar. The present study aimed to assess relation of mandibular canal wit IANC. 


\section{MATERIALS \& METHODS}

The present study was conducted in the department of Oral \& Maxillofacial Surgery. It comprised of 82 patients with impacted mandibular third molar of both gender requiring surgical extraction.

Inclusion Criteria: Patients above 18 years of age.

Exclusion Criteria: Pregnant females and poor quality radiographs.

Ethical clearance for the study was taken from institutional ethical committee. All patients were informed regarding the study and written consent was obtained in their local language.

Data pertaining to patients as name, age, gender etc. was recorded. After careful oral examination, patients were subjected to panoramic radiographs and subsequent CBCT using all standardized operating parameters. Panoramic images were obtained with Planmica machine operating at 120 $\mathrm{kVp}, 10 \mathrm{~mA}$ and with 17 seconds exposure time and CBCT machine was Kodak operating at $90 \mathrm{kVp}, 8 \mathrm{~mA}$ and 18 seconds exposure time. The canal was traced, and the image formed was evaluated in all three planes viz. sagittal, coronal, and axial planes. The obtained images were evaluated by oral maxillofacial radiologist for the assessment of its relation. Results thus obtained were subjected to statistical analysis. $\mathrm{P}$ value $<0.05$ was considered significant.

\section{RESULTS}

Out of 82 patients, males were 48 and females were 34 (Table-1, Graph-1). Darkening of roots (DR) was seen in 14 males and 10 females, diversion of canal (DC) in 10 males and 6 females, narrowing of canal (NC) in 8 males and 5 females, presence of cortication in 10 males and 7 females and interruption of white line (IWL) in 6 males and 6 females (Table-2, Graph-2). The difference was significant $(\mathrm{P}<0.05)$. Third molar relation with IAC was class 0 seen in 0 patients, subtype $1 \mathrm{~A}$ in 12 , subtype $1 \mathrm{~B}$ in 14 , subtype $2 \mathrm{~A}$ in 2 , subtype $2 \mathrm{~B}$ in 1 , subtype $3 \mathrm{~A}$ in 21 , subtype $3 \mathrm{~B}$ in 13 , subtype $4 \mathrm{~A}$ in 2 , subtype $4 \mathrm{~B}$ in 11 , subtype $5 \mathrm{~A}$ in 1 , subtype $5 \mathrm{~B}$ in 2 , subtype $6 \mathrm{~A}$ in 1 , subtype $6 \mathrm{~B}$ in 1 and class 7 in 1 (Graph-3). The difference was significant $(\mathrm{P}<0.05)$.

Table-1: Distribution of patients

\begin{tabular}{|c|c|c|}
\hline \multicolumn{3}{|c|}{ Total- 82 } \\
\hline Gender & Males & Females \\
\hline Number & 48 & 34 \\
\hline
\end{tabular}

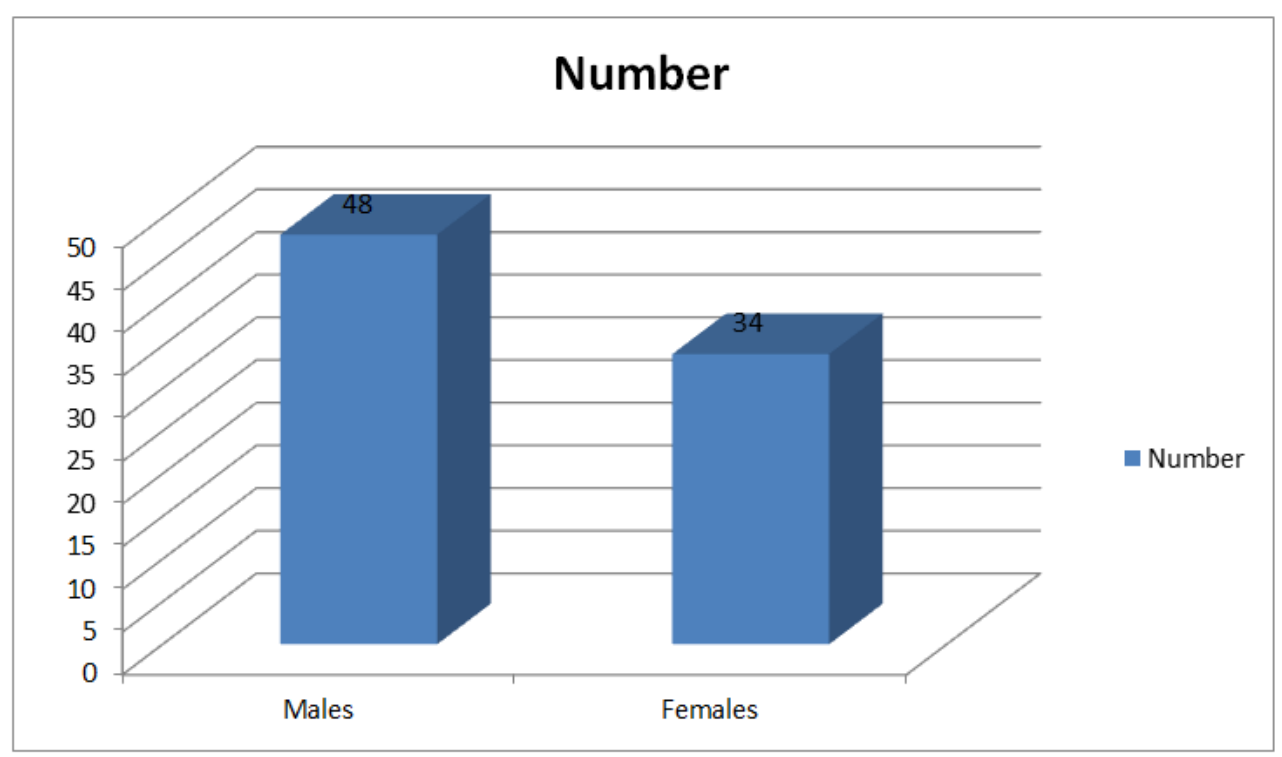

Graph-1: Distribution of patients

Table-2: Radiographic signs on Panoramic images

\begin{tabular}{|c|c|c|c|}
\hline Signs & Males & Females & P value \\
\hline Darkening of roots (DR) & 14 & 10 & \multirow{2}{*}{0.05} \\
\cline { 1 - 2 } Diversion of canal (DC) & 10 & 6 & \\
\cline { 1 - 2 } Presence of cortication (PC) & 8 & 5 & \\
\cline { 1 - 3 } Narrowing of canal (NC) & 10 & 7 & \\
\cline { 1 - 3 } Interruption of white line (IWL) & 6 & 6 & \\
\hline
\end{tabular}

Mann Whitney test, $p<0.05$ (Significant) 


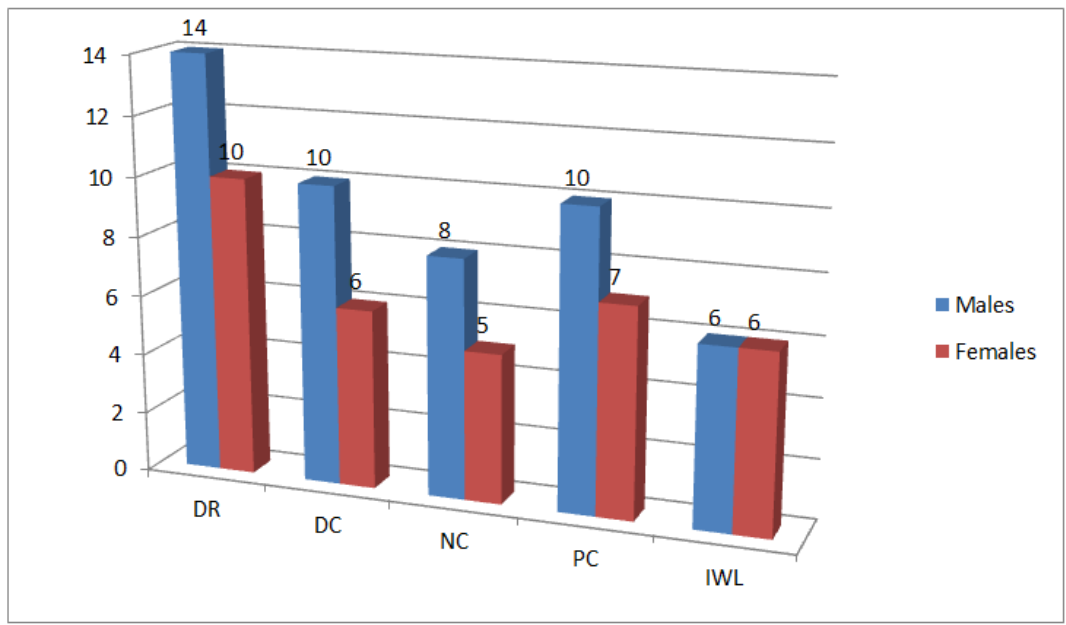

Graph-2: Radiographic signs on panoramic images

Table-3: Classes and subtypes of the CBCT radiological classification

\begin{tabular}{|c|c|}
\hline Classes & Number \\
\hline 0 & 0 \\
\hline $1 \mathrm{~A}$ & 12 \\
\hline 1B & 14 \\
\hline $2 \mathrm{~A}$ & 2 \\
\hline $2 \mathrm{~B}$ & 1 \\
\hline $3 \mathrm{~A}$ & 21 \\
\hline 3B & 13 \\
\hline $4 \mathrm{~A}$ & 2 \\
\hline 4B & 11 \\
\hline $5 \mathrm{~A}$ & 1 \\
\hline $5 \mathrm{~B}$ & 2 \\
\hline $6 \mathrm{~A}$ & 1 \\
\hline $6 \mathrm{~B}$ & 1 \\
\hline 7 & 1 \\
\hline
\end{tabular}

Mann Whitney test, $p<0.05$ (Significant)

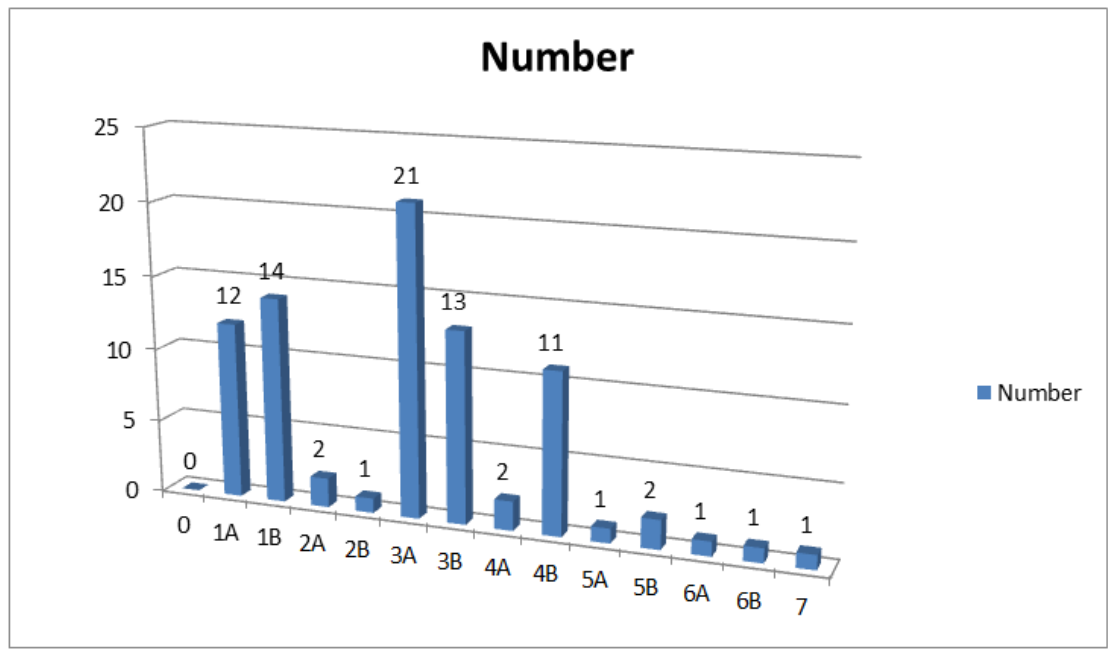

Graph-3: Classes and subtypes of the CBCT radiological classification

\section{DISCUSSION}

Mandibular third molar is frequently impacted molar. Several studies have been conducted on mentioning risk factors and complications linked with the disimpaction of impacted mandibular third molars.
Damage to IAN during surgical procedure is commonly encountered. Radiographic examination may be useful before planning surgical procedure. OPG is routinely performed in clinical practice before extraction $[5,6]$. 
The present study aimed to assess relation of mandibular canal wit IANC.

In present study, there were 82 patients which had 42 males and 38 females. We subjected all patients to panoramic and CBCT. Most commonly seen criteria was darkening of roots followed by diversion of canal (DC), interruption of white line (IWL), narrowing of canal (NC) and presence of cortication.

In this study, we found that darkening of roots (DR) was seen in 14 males and 10 females, diversion of canal (DC) in 10 males and 6 females, narrowing of canal (NC) in 8 males and 5 females, presence of cortication in 10 males and 7 females and interruption of white line (IWL) in 6 males and 6 females.

Susarla et al., [7] in their study determined the association between computed tomographic (CT) assessment of inferior alveolar nerve (IAN) canal cortical integrity and intraoperative IAN exposure on 51 subjects (57\% female) with a mean age of $35.2+/-12.8$ years. Of the 80 third molars, 52 third molars $(64.1 \%)$ had evidence of loss of cortical integrity. The mean cortical defect length was $2.9+/-2.6 \mathrm{~mm}$. Loss of cortical integrity had a high sensitivity $(>$ or $=0.88$ ) but low specificity $(<$ or $=0.49)$ as a diagnostic test for IAN visualization. A cortical defect size $>$ or $=3 \mathrm{~mm}$ was associated with an increased risk for intraoperative IAN visualization with a high sensitivity and specificity (> or $=0.82$ ).

We found that Third molar relation with IAC was class 0 seen in 0 patients, subtype $1 \mathrm{~A}$ in 12 , subtype $1 \mathrm{~B}$ in 14 , subtype $2 \mathrm{~A}$ in 2 , subtype $2 \mathrm{~B}$ in 1 , subtype $3 \mathrm{~A}$ in 21 , subtype $3 \mathrm{~B}$ in 13 , subtype $4 \mathrm{~A}$ in 2 , subtype $4 \mathrm{~B}$ in 11 , subtype $5 \mathrm{~A}$ in 1 , subtype $5 \mathrm{~B}$ in 2 , subtype $6 \mathrm{~A}$ in 1 , subtype $6 \mathrm{~B}$ in 1 and class 7 in 1 .

Tantanapornkul et al., [8] found CBCT superior as compared to panoramic radiographs in assessing neurovascular bundle exposure following assessment of the relationship of the mandibular third molar root tip to the mandibular canal. 161 impacted mandibular third molar teeth were studied and there was $93 \%, 77 \%$ and $70 \%, 63 \%$ of relative sensitivity and specificity of CBCT and OPG In this study we found that maximum number of subtype $3 \mathrm{~A}$ relation was seen followed by subtype $1 \mathrm{~B}$, subtype $3 \mathrm{~A}$, subtype $3 \mathrm{~B}$, subtype 1A, subtype 4B etc.

Nayak et al., [9] in their study evaluated rerlation between OPG, CBCT and mandibular thirds molar and found that twenty-one samples (52.5\%) showed darkening of the apex, which was the most frequent type of radiographic sign of a close relationship on panoramic radiography. Twenty-three samples $(57.5 \%)$ revealed a true relationship on CBCT. Darkening of the apex and narrowing of the canal were the signs most frequently associated with a true relationship. On CBCT, coronal and axial sections better predicted a true relationship.

Park et al., [10] in their study assessed relationship between the IAC and the MTM as viewed on a CT image, classified into three groups: group 1, no contact; group 2, contact between the MTM and the intact IAC cortex; group 3, contact between the MTM and the interrupted IAC cortex. There were 179 participants who underwent MTM extraction (a total of 259 MTMs). Their mean age was 23.6 years, and 85 (47.5 percent) were male. The overall prevalence of paresthesia was 4.2 percent (11 of 259 teeth). The prevalence of paresthesia in group 3 (involving an interrupted IAC cortex) was 11.8 percent (10 of 85 cases), while for group 2 (involving an intact IAC cortex) and group 1 (involving no contact) it was 1.0 percent (1 of 98 cases) and 0.0 percent (no cases), respectively. The frequency of nerve damage increased with the number of CT image slices showing loss of cortical integrity $(P=.043)$.

The limitation of the study is small sample size. The inclusion of large number of patients could have been proved useful in assessing different relation of mandibular third molar with inferior alveolar nerve canal.

\section{CONCLUSION}

Authors found that impacted mandibular third molar surgery may lead to damage to inferior alveolar canal. Therefore a radiographic imaging with OPG and CBCT may be useful in preventing damage to the nerve.

\section{REFERENCES}

1. Xu, G. Z., Yang, C., Fan, X. D., Yu, C. Q., Cai, X. Y., Wang, Y., \& He, D. (2013). Anatomic relationship between impacted third mandibular molar and the mandibular canal as the risk factor of inferior alveolar nerve injury. British Journal of Oral and Maxillofacial Surgery, 51(8), e215-e219.

2. Neves, F. S., Souza, T. C., Almeida, S. M., HaiterNeto, F., Freitas, D. Q., \& Bóscolo, F. N. (2012). Correlation of panoramic radiography and cone beam CT findings in the assessment of the relationship between impacted mandibular third molars and the mandibular canal. Dentomaxillofacial radiology,41(7), 553 557.

3. Guerrero, M. E., Nackaerts, O., Beinsberger, J., Horner, K., Schoenaers, J., Jacobs, R., \& SEDENTEXCT Project Consortium. (2012). Inferior alveolar nerve sensory disturbance after impacted mandibular third molar evaluation using cone beam computed tomography and panoramic radiography: a pilot study. Journal of Oral and Maxillofacial Surgery, 70(10), 2264-2270. 
4. Shahidi, S., Zamiri, B., \& Bronoosh, P. (2013). Comparison of panoramic radiography with cone beam CT in predicting the relationship of the mandibular third molar roots to the alveolar canal. Imaging science in dentistry, 43(2), 105109.

5. Maglione, M., Costantinides, F., \& Bazzocchi, G. (2015). Classification of impacted mandibular third molars on cone-beam CT images. Journal of clinical and experimental dentistry, 7(2):224-231.

6. Suomalainen, A., Ventä, I., Mattila, M., Turtola, L., Vehmas, T., \& Peltola, J. S. (2010). Reliability of CBCT and other radiographic methods in preoperative evaluation of lower third molars. Oral Surgery, Oral Medicine, Oral Pathology, Oral Radiology, and Endodontology, 109(2), 276-284.

7. Susarla, S. M., Sidhu, H. K., Avery, L. L., \& Dodson, T. B. (2010). Does computed tomographic assessment of inferior alveolar canal cortical integrity predict nerve exposure during third molar surgery?. Journal of Oral and Maxillofacial Surgery, 68(6), 1296-1303.
8. Tantanapornkul, W., Okouchi, K., Fujiwara, Y., Yamashiro, M., Maruoka, Y., Ohbayashi, N., \& Kurabayashi, T. (2007). A comparative study of cone-beam computed tomography and conventional panoramic radiography in assessing the topographic relationship between the mandibular canal and impacted third molars. Oral Surgery, Oral Medicine, Oral Pathology, Oral Radiology, and Endodontology, 103(2), 253-259.

9. Nayak, D. S., Raghavan, S. A., Birur, P., Gurudath, S., \& Keerthi, G. (2017). Determination of Proximity of Mandibular Third Molar to Mandibular Canal Using Panoramic Radiography and Cone-beam Computed Tomography. Journal of Indian Academy of Oral Medicine and Radiology, 29(4), 273-277.

10. Park, W., Choi, J. W., Kim, J. Y., Kim, B. C., Kim, H. J., \& Lee, S. H. (2010). Cortical integrity of the inferior alveolar canal as a predictor of paresthesia after third-molar extraction. The Journal of the American Dental Association, 141(3), 